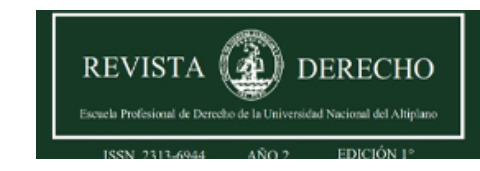

Revista de Derecho

ISSN: 2313-6944

ISSN: 2707-9651

revistaderecho@unap.edu.pe

Universidad Nacional del Altiplano

Perú

\title{
LA DESAPARICIÓN DE MUJERES Y NIÑAS EN EL ÁMBITO PERUANO E INTERNACIONAL
}

Barrios Lino, Daniela Dora; Casazola León, Johnn Adrian; Chura Godoy, Cecilia Candy; Espinoza Coila, Michael; Rojas Bellido, Kelly Cindy

LA DESAPARICIÓN DE MUJERES Y NIÑAS EN EL ÁMBITO PERUANO E INTERNACIONAL

Revista de Derecho, vol. 6, núm. 1, 2021

Universidad Nacional del Altiplano, Perú

Disponible en: https://www.redalyc.org/articulo.oa? $\mathrm{id}=671870928008$

DOI: https://doi.org/10.47712/rd.2021.v6i1.115

\section{(c) (1)}

Esta obra está bajo una Licencia Creative Commons Atribución 4.0 Internacional. 


\section{LA DESAPARICIÓN DE MUJERES Y NIÑAS EN EL ÁMBITO PERUANO E INTERNACIONAL}

\section{DISAPPEARANCE OF WOMEN AND GIRLS IN THE PERUVIAN AND INTERNATIONAL SPHERE}

Daniela Dora Barrios Lino

Universidad Nacional del Altiplano Puno, Perú

ddanidora@gmail.com

Johnn Adrian Casazola León

Círculo de Investigación Lideres Optimistas Revelando

Derecho (CILORD), Perú

adrcasazola@gmail.com

Cecilia Candy Chura Godoy

Círculo de Investigación Lideres Optimistas Revelando

Derecho, Perú

aprendiz.innerlightsound@gmail.com

Michael Espinoza Coila

Universidad Nacional del Altiplano de Puno, Perú

mespinoza@unap.edu.pe

iD https://orcid.org/0000-0002-4562-6969

Kelly Cindy Rojas Bellido

Circulo de Investigación Lideres Optimistas Revelando

Derecho (CILORD, Perú

rojaskellycindy@gmail.com
DOI: https://doi.org/10.47712/rd.2021.v6i1.115

Redalyc: https://www.redalyc.org/articulo.oa? $\mathrm{id}=671870928008$
Recepción: 18 Enero 2021

Aprobación: 09 Febrero 2021

Publicación: 10 Febrero 2021

\section{RESUMEN:}

El objetivo de este artículo es describir, los delitos de privación de la libertad al que son sometidas las mujeres y niñas específicamente al relacionado con la desaparición cometida por particulares en la cual se encuentra la trata de personas, donde brindaremos la legislación emitida por el Perú y las organizaciones internacionales, además brindaremos unos pocos delitos aledaños a los que son sometidos las personas al ser secuestradas.

Palabras Clave: Delitos, libertad, población, vulnerable, mujeres, niñas, desaparecidas, delitos, desaparición y trata de personas.

\section{AbStract:}

The objective of this article is to describe the crimes of deprivation of liberty to which women and girls are subjected, specifically related to disappearance committed by individuals in which human trafficking is found, where we will provide the legislation issued by Peru and international organizations, we will also provide a few neighboring crimes to which people are subjected when they are kidnapped. We will also seek to analyze the status of the complaints or reports of disappeared women and girls in Peru and internationally, which is why we will release the statistical data obtained, to analyze the status of the reports of disappearance in Peru internationally, in Together with the emblematic cases that we consider necessary to know, on the other hand, it offers some small scopes of the objectives of the "búscalas" campaign that was born as a response from an international organization of activists that is currently in more than 150 countries, focused to promote human rights. In this sense, the research is oriented to 
the compilation of information and a brief analysis of these based on international doctrine and experiences. Likewise, the study in the core is non-experimental, descriptive, whose instruments are content analysis and documentary sources.

KEYWORDS: Crimes, freedom, population, vulnerable, women, girls, disappeared, crimes, disappearance and human trafficking.

\section{INTRODUCCIÓN}

El presente artículo busca abordar el desarrollo conceptual de los delitos contra la libertad de tránsito más específicamente la desaparición cometida por particulares enfocado en las mujeres y niñas, asimismo se brindara una breve recopilación de la legislación concerniente a este tema, por consiguiente los delitos que se dan de forma aledaña como lo son el feminicidio y la trata de personas, en este último se desarrollara lo concerniente a las finalidades por las cuales se puede concretar este delito, al ser un estudio descriptivo se brindara una serie de estadísticas y datos que se recogieron de las entidades cuya competencia sean concordantes con el tema en investigación, además se brindará una recopilación de algunos casos emblemáticos de la desaparición de mujeres y niñas; para culminar se dará a conocer los objetivos que comprende la campaña "búscalas".

Consideramos que al describir los fundamentos sociales, pueden ayudar a la toma de conciencia para evitar el secuestro y trata de mujeres en la región andina del altiplano y en todo el Perú, razón por la cual, incentivamos a la actuación de la población en la prevención y apoyo en la resolución de dichos delitos que tienen una suma importancia, en tanto, vulneran los derechos de dos de los grupos sociales que han sufrido más a lo largo de la historia, y son de suma importancia para el correcto desarrollo de un país con vistas a mejorar en políticas públicas que puedan ayudar en su defensa nos referimos a las mujeres y las niñas.

Siendo la investigación de naturaleza cuantitativa y cualitativa hemos tenido en cuenta varios instrumentos para la recolección de datos e información, como fichas de análisis documental, fichas de recolección de datos, además de, revisión de literatura jurídica, ensayos y estudios similares.

Acorde a esto se utilizó el método científico para la cuestión cuantitativa y el análisis documental para la cuestión cualitativa, además del uso de los métodos deductivos e inductivos en la elaboración de conceptos que permitan acercarnos al entendimiento de la realidad.

\section{LA DESAPARICIÓN DE PERSONAS}

Expone Coca Guzmán (2020), que se puede establecer como una persona desaparecida cuando está "no se encuentre en su domicilio por un determinado periodo de tiempo y además que no se tengan noticias de su paradero", de similar manera se define a tenor de lo dispuesto en el artículo 5 del Decreto Legislativo N. 1428 "se considera persona desaparecida a aquella que se encuentra ausente de su domicilio habitual y respecto del cual se desconoce su paradero".

"La desaparición involuntaria de personas, seguida de la falta de información o de la negativa de informar sobre el paradero de la persona, es una realidad dolorosa para muchas familias en el mundo y en nuestro país". (Cervantes, 2015, p.3)

\subsection{DESAPARICIÓN COMETIDA POR PARTICULARES}

La diferencia entre la desaparición cometida por particulares de la denominada desaparición forzada, esta última "tiene como particularidad que el sujeto que lleva a cabo la desaparición es un agente del Estado, persona o grupo que actúa con la autorización, el apoyo o la aquiescencia del Estado" (Defensoría del Pueblo, 2020, p.5). En cambio, las desapariciones cometidas por particulares son un tipo de "desapariciones con un fenómeno social, más no político, que puede relacionarse o no con casos de trata de personas. Ello debido 
a que cualquier persona desaparecida puede ser una potencial víctima de explotación" (CHS Alternativo, 2020, párr. 1).

\subsection{DESAPARICIÓN DE MUJERES}

La Organización de Estados Americanos (2018), explica que las desapariciones llevadas a cabo por particulares responden específicamente a las dinámicas enraizadas en las relaciones desiguales de poder entre mujeres y hombres, en forma de violencia de género. La desaparición de mujeres, a menudo está vinculada con otras formas de violencia, como el feminicidio, la trata de mujeres y niñas, y la violencia sexual (Defensoría del Pueblo, 2020, p.5). Esta tendencia es preocupante por la relación que hay entre los casos de desaparecidos con otros delitos como la trata de personas y la explotación sexual.

La desaparición de mujeres y niñas llevada a cabo por particulares constituye una forma de violencia autónoma que tiene como consecuencia la vulneración de derechos como la vida, integridad física, psíquica, la libertad, derecho a una vida libre de violencia y el derecho a la igualdad. (Defensoría del Pueblo, 2020, p.5)

Si bien la desaparición de mujeres llevada a cabo por particulares no se encuentra de forma expresa dentro de la mayoría de instrumentos internacionales, "debe considerarse que se trata de una forma de violencia contra la mujer" (Defensoría del Pueblo, 2020, p.5). Por ello, se considera comprendida en las obligaciones internacionales de respeto y garantía del derecho a la igualdad de género y no discriminación que surgen de acuerdos convencionales y otros instrumentos internacionales de protección de derechos humanos, entre los cuales podemos resaltar:

- Convención sobre la Eliminación de todas las Formas de Discriminación contra la Mujer (CEDAW).

- Convención Interamericana para Prevenir, Sancionar y Erradicar la Violencia Contra la Mujer (Belém do Pará).

- Declaración y la Plataforma de Acción de la Cuarta Conferencia Mundial sobre la Mujer (Beijing, 1995)

Ahora bien, toda situación de desaparición de una persona genera obligaciones internacionales al Estado que derivan de tratados que le son vinculantes en esta materia, como la Convención Belém Do Pará. Entre estas, deben cumplir lo siguiente: (Convención Interamericana para Prevenir, Sancionar y Erradicar la Violencia contra la Mujer, 1994, Art. 7)

a) Debida diligencia: procurar una intervención de forma oportuna en los casos y destinar las diligencias mínimas de búsqueda e investigación con enfoque de género;

b) Actuación pronta e inmediata: las autoridades policiales, fiscales y judiciales deben disponer acciones necesarias para ubicar a la víctima;

c) Procesos adecuados de denuncia: se deben establecer procedimientos idóneos para las denuncias a fin de posibilitar una investigación efectiva desde las primeras horas.

d) Presunción de vida: la investigación de las autoridades debe guiarse bajo la presunción de que la persona desaparecida sigue viva y privada de su libertad;

e) Personal capacitado: las denuncias recibidas por el personal deben evitar dilaciones basadas en estereotipos y prejuicios de género.

\subsection{PERSONAS DESAPARECIDAS EN PERÚ}

\subsubsection{LEGISLACIÓN NACIONAL SOBRE PERSONAS DESAPARECIDAS.}

- Ley N ${ }^{\circ} 28022$ Crea el Registro Nacional de Información de Personas Desaparecidas.

- Decreto Supremo No 017-2003-IN. Reglamento de la Ley N² 28022 que crea el Registro Nacional de Información de Personas Desaparecidas. 
- Decreto Supremo N ${ }^{\circ}$ 002-2020-IN, que aprueba el Protocolo interinstitucional de atención de casos de desaparición de personas en situación de vulnerabilidad y otros casos de desaparición.

- Decreto Supremo No 003-2019-IN, Decreto Supremo que aprueba el Reglamento del Decreto Legislativo No 1428, Decreto Legislativo que desarrolla medidas para la atención de casos de desaparición de personas en situación de vulnerabilidad.

- Decreto Legislativo No 1428 Decreto legislativo que desarrolla medidas para la atención de casos de desaparición de personas en situación de vulnerabilidad.

- Resolución Ministerial No 003-2019-IN. Reglamento del Decreto Legislativo No 1428 que desarrolla medidas para la atención de casos de desaparición de personas en situación de vulnerabilidad.

- Resolución De Comandancia N³79-COMGEN/EMG-PNP, que aprueba las normas y procedimientos policiales en casos de desaparición de personas en situación de vulnerabilidad (niños, niñas, adolescentes, adultos mayores y personas con discapacidad, mental física o sensorial).

La entidad internacional encargada de la defensa de los derechos humanos nos referimos a la CIDH establece que los estándares exiguos son: el que los Estados mantengan un marco jurídico adecuado; distinción de circunstancias de riesgo desde un enfoque interseccional; participación e indagación esmeradas con perspectivas de género; presumir que aquella persona de la cual no se tiene información de su paradero se mantenga con vida; además buscar medidas que prevengan estos delitos. (Defensoría del Pueblo, 2020)

1.3.2 EL PORTAL Y REGISTRO NACIONAL DE INFORMACIÓN DE PERSONAS DESAPARECIDAS (RENIPED)

Actualmente el Ministerio del Interior maneja una página para coadyuvar a la búsqueda de peruanos desaparecidos como parte de la implementación de la Ley $\mathrm{N}^{\circ} 29685$ y su reglamento.

Esta página permite la difusión de las denuncias de desaparecidos en dos listas, de 0 a 17 años y de 18 años a más, en base a las alertas emitidas por la División de Investigación y Búsqueda de Personas Desaparecidas de la Policía Nacional del Perú. Y por otro lado nos permite conocer la lista de "ubicados" o personas aparecidas.

El RENIPED, es la base datos centralizada que contiene la información de las personas cuya desaparición ha sido denunciada ante la Policía Nacional del Perú. Su administración y gestión se encuentra a cargo de la PNP. La información contenida en el Reniped se articula con las bases de datos que contribuyen en la investigación, búsqueda y ubicación de personas denunciadas como desaparecidas. (Ministerio del Interior, 2020)

Este registro es la única herramienta disponible en Perú para centralizar la información relativa a las personas desaparecidas.

"El Estado no debe descuidar la búsqueda de ninguna persona desaparecida. A través de la ubicación de dichas personas se puede descubrir y desarticular redes de tratantes de personas" (CHS Alternativo, 2020).

1.3.3. LA DESAPARICIÓN DE MUJERES COMETIDAS POR PARTICULARES EN CONTEXTO DEL COVID-19 EN PERÚ

En los casos de desaparición de mujeres, resulta de vital importancia que se realicen acciones de búsqueda exhaustivas de forma inmediata a la presentación de la denuncia. Por ello, las autoridades que reciben la denuncia deben estar previamente capacitadas y no hacer uso de estereotipos de género debido a que comprometen la oportunidad de dichas acciones y pueden exponer a la víctima a mayores vejámenes (Defensoría del Pueblo, 2020, p.7)

La desaparición de mujeres es una problemática que ha persistido pese a las medidas restrictivas de la libertad de tránsito adoptadas frente a la pandemia del COVID-19. La problemática de la desaparición, a raíz de la propagación del COVID-19, puede verse marcada por las medidas restrictivas de tránsito, que no solo dificultan la interposición de denuncias presenciales, sino que imposibilitan a las familias a realizar sus propias acciones de búsqueda. Otro factor que se debe tener en cuenta son los altos índices de feminicidio durante el periodo de aislamiento social; cabe recordar que la desaparición puede constituir un paso previo para la comisión de este delito. (Defensoría del Pueblo, 2020, pp.31-32) 
En este contexto generado por la pandemia del COVID-19, se considera en especial situación de riesgo a las mujeres desaparecidas, quienes pueden sufrir mayores afectaciones a sus vidas e integridades. Por ello, es necesario la priorización de acciones dirigidas a su búsqueda y ubicación; la implementación de mecanismos tecnológicos adecuados (registro y portal); y la activación y difusión de canales de denuncia, que tengan en cuenta las restricciones a la libertad de tránsito. (Defensoría del Pueblo, 2020, p.35)

\section{DELITO DE TRATA DE PERSONAS}

Para la Interpol (2020), "La trata de personas es una forma de delincuencia organizada internacional, valorada en miles de millones de dólares, que constituye una forma de esclavitud en nuestros tiempos. " (Trata de Personas, párrafo 1) Como sinónimo de "esclavitud", que hace referencia a la imposibilidad del esclavo de ejercer su voluntad y sustraerse al vínculo sin poner en peligro su vida, se ha convertido en una categoría de difusión de vasta.

Según el artículo $3^{\circ}$ del Protocolo para prevenir, reprimir y sancionar la trata de personas, especialmente mujeres y niños, que complementa la Convención de las Naciones contra la Delincuencia Organizada Transnacional, la trata de personas es la captación, el transporte, el traslado, la acogida o la recepción de personas, recurriendo a la amenaza o al uso de la fuerza u otras formas de coacción, al rapto, al fraude, al engaño, al abuso de poder o de una situación de vulnerabilidad o a la concesión o recepción de pagos o beneficios para obtener el consentimiento de una persona que tenga autoridad sobre otra, con fines de explotación. Esa explotación incluirá, como mínimo, la explotación de la prostitución ajena u otras formas de explotación sexual, los trabajos o servicios forzados, la esclavitud o las prácticas análogas a la esclavitud, la servidumbre o la extracción de órganos. (Protocolo para prevenir, reprimir y sancionar la trata de personas, especialmente mujeres y niños, que complementa la Convención de las Naciones contra la Delincuencia Organizada Transnacional, 2000)

Nos ilustra Tejada (2016), el delito de «trata de personas» implica un comportamiento prohibido relacionado con el proceso de captación, transporte, traslado, acogida, recepción o retención de una persona, en el territorio de la República o de paso por el país, con fines de explotación u otros fines ilegales de este mismo carácter, pudiendo reputarse válidamente, a propósito, como una nueva forma de esclavitud, un delito transnacional y hasta un crimen de lesa humanidad al violentar con su perpetración derechos humanos consagrados, específicamente la libertad, la dignidad, la seguridad personal, el acceso a la justicia, el derecho a no ser sometido a la esclavitud, la servidumbre, los trabajos forzosos, el derecho a no ser sometido a torturas, el derecho a no ser objeto de violencia por motivos de género, la libertad de circulación, la salud física y mental, el derecho a condiciones de trabajo justas y favorables, el derecho a un nivel de vida adecuado, el derecho a la seguridad social y el derecho a no ser vendido ni ser objeto de comercio. (p. 349)

Según Uribe (2013) en el concepto de trata de personas se pueden identificar tres elementos básicos: la conducta punible (captar, trasladar o recibir a una persona); los medios con los que se llegan a cometerla (violencia, engaño, abuso del poder, etcétera), y la consecuencia a la que llega (la explotación de la víctima).

La trata de personas es, en efecto, un problema social que desborda las consideraciones jurídicas y victimológicas tradicionales. Es un delito en muchos casos relacionados a la criminalidad organizada, con graves consecuencias para los derechos humanos y la seguridad ciudadana en el país, respecto del cual urge persistir en el sendero de estrategias y políticas implementadas y reunidas por las instituciones en pro de los Derechos Humanos.

Este delito que además adquiere la denominación de "la esclavitud del siglo XXI" suele recaer en otras modalidades que pueden ser: la experimentación biomédica ilícita, servicios o trabajos forzados, explotación laboral y/o sexual, mendicidad y en algunos casos el matrimonio forzoso. (Cendejas Jauregui, Pérez Morales, Rivas Rodríguez \& Fernández Hernández, 2014) 


\subsection{FINES DE LA TRATA DE PERSONAS}

\subsubsection{Explotación sexual}

Se refiere a la "utilización del cuerpo de una persona como objeto sexual a cambio de dinero o especies" (CHS Alternativo, 2010, p.13).

A pesar de contar con un amplio marco normativo de prevención, atención y sanción a nivel internacional y nacional en los delitos de trata de personas, ese marco no logra traducirse en hechos. La deficiente sanción y protección de las víctimas se expresa en la elevada tasa de agraviadas por este delito. Esta situación es especialmente preocupante en grupos altamente vulnerables como son las mujeres, las niñas, los niños y los adolescentes, que de acuerdo a la Oficina de las Naciones Unidas contra la Droga y el Delito (Unodc), las víctimas del delito de trata fueron mayoritariamente mujeres (71\% en el 2016), lo que incluye a niñas, adolescentes y adultas, que son captadas por sus tratantes para posteriormente ser explotadas sexualmente. (Defensoría del Pueblo, 2017, p.8)

"Los registros oficiales sobre víctimas de trata en el Perú indican que la mayoría son mujeres y niñas" (Ministerio de Justicia y Derechos Humanos [MINJUS], 2017, p. 28). Para la Interpol (2020, Trata de mujeres para su explotación sexual, párrafos 1 y 2):

Esta frecuente forma de trata afecta a todas las regiones del mundo, bien como país de origen, tránsito o destino. En los países en vías de desarrollo y también en segmentos vulnerables de la población de los países desarrollados, se embauca a mujeres y niños con la promesa de un buen empleo si se marchan de sus casas y viajan a lo que consideran que será una vida mejor.

Las víctimas reciben a menudo documentos de viaje falsos. Una red organizada las transporta al país de destino donde se ven sometidas a explotación sexual, y se les mantiene permanentemente aterrorizadas y en condiciones inhumanas. Además de ello, las víctimas sufren graves secuelas físicas y psicológicas por la explotación sexual continuada. (Giménez-Salinas, 2011)

Para proteger a estas víctimas vulnerables e inocentes, podemos enfocarnos en la demanda efectiva y perseguir enérgicamente a los perpetradores de la trata de personas, donde talvez la ley penal pueda ser un freno vigoroso y seguro que pueda impedir la conducta delictiva. (Bernstein, 2014)

2.1.2. La explotación sexual comercial infantil

La explotación sexual comercial es considerada como una de las peores formas de trabajo infantil que responde a múltiples causas y su dinámica trasciende el ámbito de un contexto social particular, de una clase socioeconómica determinada o de un grupo social específico (Organización Internacional del Trabajo [OIT], 2002, pp. 11-14)

El término "Explotación Sexual Comercial Infantil" Implica el sometimiento del cuerpo y la voluntad de las víctimas inocentes, despojándolas así de sus más elementales derechos humanos. Así mismo, esta forma de explotación siempre constituye una forma de coerción y violencia contra las niñas, niños y adolescentes, pudiendo interpretarse como un trabajo forzoso y una forma contemporánea de esclavitud. La explotación sexual comercial infantil tiene tres modalidades principales: Las relaciones sexuales remuneradas (mal llamada prostitución infantil) que tiene a su vez dos vías de expresión: la demanda local y la trata con propósitos sexuales, la pornografía utilizando niñas, niños y adolescentes, y el turismo sexual (CHS Alternativo, 2010, p.13-14).

Estudia Hernández (2005, p.9), sobre la explotación sexual comercial:

como violación de derechos, y como fenómeno que implica serias huellas psicológicas en términos de sufrimiento por la violencia reiterada recibida, tiene como uno de sus efectos principales el que las personas menores de edad recurran al consumo de sustancias psicoactivas como una forma de anestesiar o poder sobrellevar las experiencias de explotación sexual sufridas, e inclusive necesidades básicas no satisfechas, mitigando las sensaciones de hambre o dolor físico.

\subsubsection{Mendicidad}

Como lo explica Álvarez, L. Buitrago, L. \& Fajardo, G. (2019): 
La lucha contra la trata de personas como problemática mundial se ha convertido en prioridad para todos los países, dada su grave vulneración y afectación a los derechos humanos de especial protección. Dentro de sus modalidades de acción se encuentra la mendicidad ajena, en la cual la persona, una vez puesta en condiciones indignas, es obligada a pedir limosna con el fin de obtener un beneficio para un tercero, lo que constituye un modo de explotación laboral al cual son más propensas la infancia y la adolescencia, sobre todo de comunidades indígenas (pp.129-130).

La mendicidad se presenta como una figura más en la trata de personas pues involucra otra forma de explotación y esclavitud, siendo las niñas y niños la población más vulnerable. Los niños y niñas son usadas como objeto para inspirar lástima en las personas. Se ha identificado que la mendicidad se da en tres direcciones: por un lado, la propia comercialización del niño o niña por parte de los padres que se convierten en mendigos, utilizando a su hijo como instrumento para acceder a la compasión social, en segundo lugar, el alquiler de niños y niñas por parte de los padres a personas que los utilizaran para el mismo fin, y en tercer lugar las desapariciones de menores de edad, que se ha ido incrementando, hace presumir un similar destino (CHS Alternativo, 2010, pp.14-15).

\subsubsection{La explotación laboral}

Las personas víctimas de la explotación laboral que caen en redes de comercializadores de seres humanos para el trabajo forzado y la servidumbre, son en su mayoría niños niñas y adolescentes que se caracterizan por sus carencias económicas y no tienen un núcleo familiar constituido. Los comercializadores los reclutan ofreciéndoles una mejora laboral y económica con un trabajo y un lugar donde vivir en la capital a cambio de entregar un porcentaje de las ganancias de su trabajo diario. Esta situación degenera en trabajo forzoso y explotación, pues son coaccionados a trabajar en situaciones que atentan contra su salud física y psicológica. Además, estos menores de edad son iniciados en el vicio de las drogas y el alcohol para crearles dependencia y mantener la situación de explotación- (CHS Alternativo, 2010, p.15).

Es un delito que instrumentaliza al ser humano para la consecución de determinadas finalidades mercantilistas, la víctima cae en una situación que lo anula como persona. Además, en contra de su voluntad, o bien sin consentimiento válido. Precisamente en atención a los fines que persigue, el delito de trata de naturaleza laboral, el delito de trata también supone la puesta en peligro de aquellos otros bienes jurídicos protegidos por los delitos a través de los que se manifieste el objetivo explotador: delitos contra los derechos de los trabajadores, libertad sexual, integridad o salud física, integridad moral, etc. Se distingue la explotación laboral, por razones relativas al bien jurídico afectado, entre obligar a desempeñar un servicio o trabajo en régimen de esclavitud o análogo, por un lado, e imponer condiciones de trabajo ilícitas y perjudiciales para los derechos socio-laborales, por otro (Pomares, 2011, pp. 6-8).

a. Explotación doméstica

El trabajo doméstico es fuente de explotación debido a la falta de conocimiento de los derechos de las trabajadoras del hogar, así como al poco respeto que tiene esta actividad para el imaginario social. Ya que no existe una especificidad de funciones para una persona que brinda servicio doméstico, la persona es sometida a una adjudicación infinita de tareas y obligaciones, lo que genera un alto riesgo de maltrato y explotación. Según los estudios, en el Perú las personas víctimas de la trata de personas para la explotación doméstica, son en su mayoría niñas, niños y adolescentes que trabajan en labores domésticas, en gran mayoría mujeres, lo que significa que no solo es un problema de pobreza sino una grave diferenciación de roles por género. (CHS Alternativo, 2010, pp15-16).

b. Trabajo forzado y servidumbre

El derecho a trabajar en libertad y dignidad, sin trabajo forzoso es un derecho humano laboral. Según la Organización Internacional del Trabajo (2021):

Por trabajo forzoso puede entenderse el trabajo que se realiza de manera involuntaria y bajo amenaza de una pena cualquiera. Se refiere a situaciones en las cuales personas están forzadas a trabajar mediante el uso de violencia o intimidación, o por medios más sutiles como una deuda manipulada, retención de documentos de identidad o amenazas de denuncia a las autoridades de inmigración (¿Qué es el trabajo forzoso?, párr.1). 
El trabajo forzoso involucra una condición de esclavitud y reclutamiento obligatorio, que expone a la víctima a abusos de índole físico, psicológico y sexual que mellan su desarrollo personal (CHS Alternativo, 2010, p.16).

Para la Interpol (2021):

Las víctimas de esta extendida forma de trata proceden principalmente de países en desarrollo. Son captadas y sometidas a trata mediante engaño y coacción, y son retenidas en condiciones de esclavitud realizando una serie de trabajos. Según el Convenio número 29 sobre el trabajo forzoso de la Organización Internacional del Trabajo (1930), el trabajo forzoso u obligatorio designa: "todo trabajo o servicio exigido a un individuo bajo la amenaza de una pena cualquiera y para el cual dicho individuo no se ofrece voluntariamente" (Art.2).

c. Trabajo peligroso

Es un "Trabajo" que pone en riesgo la salud, seguridad y moral de los niños, niñas y adolescentes por la naturaleza de la labor o el número de horas trabajadas. Este tipo de "trabajo" puede perjudicar al niño por la tarea en sí que hay que realizar, por los instrumentos que se utilizan, por los horarios o condiciones de trabajo. También puede haber otros factores que afecten el desarrollo físico, mental, emocional, psicológico, moral o espiritual de los menores (CHS Alternativo, 2010, p.17).

Minas y canteras. En el caso de la minería se secuestra o engaña a la víctima con ofertas de empleo temporal. La exposición temprana a estos riesgos afecta a los niños debido a la inmadurez de su organismo, sus mayores necesidades, menor resistencia, su alta capacidad de absorción y vulnerabilidad psicológica. (CHS Alternativo, 2010).

Basureros. El trabajo en los basurales (Segregación) consiste en la recuperación de una amplia gama de materiales que luego son comercializados para su reutilización o reciclaje, a través de empresas en su mayoría clandestinas.

Los niños, niñas y adolescentes son usados por mafias para la recolección y segregación de basura. Los riesgos en los basurales son muchos, y más si se toma en cuenta que la mayoría de las veces estos menores de edad viven en entornos, en condiciones infrahumanas, siendo víctimas de infecciones, enfermedades digestivas, malnutrición, cortes con vidrios, contacto con jeringas y desechos hospitalarios, mordeduras de animales, picaduras de insectos, atropellos y acoso.

Mercados. Cada día, en los mercados de América Latina y el Caribe miles de niños, niñas y adolescentes compiten con los adultos en múltiples tareas y jornadas que van desde las cuatro de la mañana hasta las seis de la tarde. Trabajan con familias, generalmente de origen provinciano, las mismas que los han sacado de su comunidad de origen, quienes tienen un puesto en el mercado o son carretilleros. Para esos menores tener el mercado y la calle como espacio de socialización, trae grandes riesgos para su integridad física y moral.

Sector informal. El "sector informal" es la parte de la economía que incluye las actividades generadoras de ingresos donde su no es "oficial"; no hay ninguna entidad gubernamental o autoridad tributaria que sepa que están trabajando, porque no están oficialmente empleados. En muchos casos, las personas para las que trabajan no están registradas como empleadores.

El sector informal es un término genérico para actividades que van desde las que generan los menores ingresos (limpiar zapatos o cuidar carros) hasta empresas más productivas con varios empleados (pesca a pequeña escala, minería, explotación de canteras, ladrilleras, actividades agrícolas y comerciales, talleres, entre otros).

2.1.5. Trata de personas para la extracción de órganos

En muchos países las listas de espera para el trasplante de órganos son muy largas, y los delincuentes han aprovechado esta situación para lucrarse a costa de la desesperación de los pacientes y donantes potenciales. La salud de las víctimas, incluso sus vidas, se pone en peligro, pues las operaciones pueden realizarse clandestinamente sin seguimiento médico. (INTERPOL, 2020) 
Aunque no existen datos, informes periodísticos dan cuenta de personas que han sido drogadas y, posteriormente, halladas con extrañas cicatrices o sin un órgano. Otros indicios apuntan al secuestro para el tráfico de órganos y tejidos hacia países desarrollados. (CHS Alternativo, 2010)

\subsubsection{Venta de Niños}

La venta de niños, puede aparecer en las modalidades de explotación sexual, transferencia de órganos, trabajo forzado y adopción. (Red Para La Infancia y la Adolescencia, 2009, p.4)

En los últimos años diversos órganos de las Naciones Unidas dedicados a la protección de los derechos humanos se han ocupado de forma específica de lo que se denomina genéricamente la "trata de niños", y de otras modalidades de explotación infantil como la "venta de niños", la "prostitución infantil" o "la utilización de los niños en la pornografía”. Todos ellos son fenómenos muy complejos, de dimensiones globales, interrelacionados entre sí y difíciles de desligar unos de otros, que tienen un denominador común: la explotación del niño o la niña, su reducción a un simple objeto de mercancía desconociendo su dignidad como ser humano (Salamanca, 2003, p.1).

Los padres o tutores permiten la adquisición o cesión de sus hijos por un pago en efectivo o bienes, para la explotación sexual o laboral, mendicidad, etc. Por lo general firman un papel y “dan en adopción” a sus hijos. No existe documentación relevante sobre este tema. En las zonas alejadas de las urbes este problema acontece con frecuencia, sin embargo, no quedan registrados. (CHS Alternativo, 2010, p.19)

\section{TABLA 1}

Tipos de finalidades por el cual se realiza el delito de trata de personas

\begin{tabular}{|c|c|}
\hline Tipos & Dónde se hallan \\
\hline Sexual & $\begin{array}{l}\text { Explotación sexual comercial infantil, prostitución forzada, } \\
\text { pornografía (películas, fotos, internet), pedofilia, turismo sexual, } \\
\text { agencias matrimoniales, embarazos forzados. }\end{array}$ \\
\hline Mendicidad & $\begin{array}{l}\text { Mendigos adultos con niños o niñas menores de } 3 \text { años. Niños, } \\
\text { niñas y adolescentes organizados en las calles como limpia lunas o } \\
\text { lava carros. }\end{array}$ \\
\hline Laboral & $\begin{array}{l}\text { Fábricas, trabajo en canteras, segregación de basura, talleres } \\
\text { pirotécnicos, fabricación de ladrillos, mineria artesanal, tala de } \\
\text { árboles, buscadores de oro, trabajo agrícola, plantaciones de coca, } \\
\text { pesca, mendicidad, venta ambulatoria, lustrabotas, limpiadores de } \\
\text { carros, trabajo doméstico. }\end{array}$ \\
\hline $\begin{array}{l}\text { Tráfico de } \\
\text { órganos }\end{array}$ & $\begin{array}{l}\text { Sustracción ilícita de órganos, tejidos o componentes (pulmón, } \\
\text { riñón, córnea, hígado, corazón, etc.) para ser vendidos en el } \\
\text { mercado negro, vientres de alquiler. }\end{array}$ \\
\hline $\begin{array}{l}\text { Venta de niñas } \\
\text { y niños }\end{array}$ & $\begin{array}{l}\text { Adopciones irregulares. Captura, adquisición o cesión de un } \\
\text { individuo para explotación o servilismo }\end{array}$ \\
\hline
\end{tabular}

\section{CHS ALTERNATIVO}

Estos delitos revisten una serie de factores que pueden explicar su comisión entre ellos: la facilidad de comunicación actual, desigualdad social, la globalización y los conflictos políticos (estos últimos que son tan comunes en nuestra región de América latina); son los que aumentan la comisión de la trata de personas, así como, las diversas finalidades con las cuales se cometen. (Giménez-Salinas Framis, 2011) 


\section{DELITOS RELACIONADOS A LA DESAPARICIÓN DE MUJERES}

\subsection{FEMINICIDIO:}

El feminicidio palabra utilizada por primera vez por Diana Russel y Jill Radford en 1992, es el equivalente a homicidio de mujeres, es un delito que abarca todo tipo de crimen cometido contra las mujeres por su condición de mujer, es un problema multidimensional que visualiza una situación de violencia sistemática y silenciada durante muchos siglos por la indiferencia y tolerancia social. (Anaya 2012, p. 7).

El delito de feminicidio guarda relación con múltiples casos de desaparición de mujeres registrados en el Perú y en el resto de países de América Latina. Esto refleja el deficiente cumplimiento de los Estados del deber de prevención y obligación de debida diligencia en contextos de violencia de género, ya que, en muchos países, los actos de violencia hacia la mujer al igual que los estereotipos de género se encuentran generalizados y traen consigo obstáculos para la realización de denuncias policiales, investigaciones fiscales y el acceso a la justicia cada vez que se suscita un hecho de esta naturaleza.

1) Jurisprudencia de la Corte Interamericana de Derechos Humanos (CIDH)

$\mathrm{La} \mathrm{CIDH}$ al desarrollar jurisprudencia sobre el deber de prevenir violaciones a los derechos humanos de las mujeres y niñas, ha abordado el tema de la desaparición de mujeres como consecuencia del delito de feminicidio en los siguientes casos.

Caso Gonzáles y otras (campo algodonero) Vs. México. Importar lista

Conforme figura en la ficha técnica de la Jurisprudencia de la CIDH, el caso se refiere a la responsabilidad internacional del Estado por falta de diligencia en las investigaciones relacionadas a la desaparición y muerte de Claudia Ivette Gonzáles, Esmeralda Herrera Monreal y Laura Berenice Ramos Monárrez.

Los hechos sucedieron en el estado de Juárez, ciudad donde se desarrollan diversas formas de delincuencia organizada. Asimismo desde 1993 existe un aumento de homicidios de mujeres influenciado por una cultura de discriminación contra la mujer.

Laura Berenice Ramos, estudiante de 17 años de edad, desapareció el 22 de septiembre de 2001. Claudia Ivette Gonzáles, trabajadora en una empresa maquilladora de 20 años de edad, desapareció el 10 de octubre de 2001. Esmeralda Herrera Monreal, empleada doméstica de 15 años de edad desapareció el lunes 29 de octubre de 2001. Sus familiares presentaron las denuncias de desaparición. No obstante, no se iniciaron mayores investigaciones. Las autoridades se limitaron a elaborar los registros de desaparición, los carteles de búsqueda, la toma de declaraciones y el envío del oficio a la Policía Judicial.

El 6 de noviembre de 2001 se encontraron los cuerpos de Claudia Ivette Gonzáles, Esmeralda Herrera Monreal y Laura Berenice Ramos Monárrez, quienes presentaban signos de violencia sexual. Se concluyó que las tres mujeres estuvieron privadas de su libertad antes de su muerte. A pesar de los recursos interpuestos por sus familiares, no se investigó ni se sancionó a los responsables.

De esta forma, la CIDH evidenciado el siguiente problema: La prevalencia de estereotipos de género, es decir, pre-concepciones de "atributos o características poseídas o papeles que son o deberían ser ejecutados por hombres y mujeres respectivamente", se vieron reflejados en las políticas y prácticas de los funcionarios estatales en su razonamiento y en su lenguaje, ya que indicaron a los familiares de las víctimas que las buscarían sólo luego de transcurridas 72 horas e insinuaron que dichas mujeres posiblemente se habrían ido con un hombre.

Asimismo, este tribunal señaló que:

- Los Estados deben adoptar medidas integrales para cumplir con la debida diligencia en los casos de violencia contra las mujeres. Para ello, es necesario contar con un adecuado marco jurídico de protección que sea aplicado de manera efectiva y con políticas de prevención y prácticas que permitan que los funcionarios públicos puedan desplegar una actuación eficaz ante las posibles denuncias. 
- El contexto de violencia presente en ciudad Juárez al momento que desaparecieron las tres jóvenes requería que las autoridades realizaran una búsqueda exhaustiva de las misma durante las primeras horas de reportada la desaparición ante el riesgo real e inmediato de que fueran víctimas de violencia sexual y asesinato.

b. Caso Véliz Franco y otros Vs. Guatemala:

El 16 de diciembre de 2001, Rosa Franco, madre de Isabel Véliz Franco, denunció ante las autoridades guatemaltecas la desaparición de su hija de 15 años, sin embargo, no se realizó ninguna diligencia para dar con su paradero; el día 18 fue encontrada muerta y con indicios de abuso sexual. La parte querellante adujo el mal manejo de la escena del crimen y de las evidencias, el retraso en la práctica de diligencias, el sesgo de la información, la discriminación contra su familia, la estigmatización de la víctima y las amenazas de muerte contra Franco luego de iniciar el proceso de búsqueda de justicia.

La CIDH evidenció un contexto de alto nivel de violencia contra las mujeres y niñas en Guatemala y de impunidad de los culpables en tales hechos. Existía, en ese momento, una escalada de violencia y homicidios contra mujeres por razones de género, cuyas víctimas eran sobre todo mujeres residentes en barrios populares, que se dedicaban a actividades productivas no calificadas o eran estudiantes. El patrón de violencia incluía la brutalidad ejercida contra la víctima, los signos de violencia sexual, la mutilación del cadáver y los secuestros antes del asesinato, constatándose un ensañamiento desproporcionado contra las víctimas por parte de los autores de tales crímenes.

En dicha sentencia, la Corte señaló lo siguiente:

- El Estado no adoptó una sola acción para proteger a María Isabel y prevenir lo ocurrido. las obligaciones especiales de protección que el Estado Guatemalteco estaba obligado a procurar a María Isabel en razón de su condición de niña y del incremento de asesinatos de mujeres que se registraban desde Ia época de los hechos de acuerdo a Ia información de Ia Policía Nacional Civil, órgano que recibió la denuncia por su desaparición.

- El Estado tuvo conocimiento de que existía un riesgo real e inmediato de que las víctimas fueran agredidas y asesinadas. En consecuencia, consideró que frente a este conocimiento: Surge un deber de debida diligencia estricta frente a denuncias de desaparición de mujeres, respecto a su búsqueda durante las primeras horas y los primeros días. Esta obligación de medio, al ser más estricta, exige Ia realización exhaustiva de actividades de búsqueda.

- El Estado de Guatemala incumplió de forma flagrante sus obligaciones derivadas de Ia Convención Americana y reforzadas por Ia Convención Belém do Pará, al no adoptar medidas para que Ia institucionalidad del Estado siquiera emprendiera alguna acción de cara a Ia denuncia de desaparición.

- La "obligación de combatir Ia impunidad se ve acentuada cuando se trata de violaciones cuyas víctimas son niños”. A pesar de ello, el Estado de Guatemala no solo no protegió a María Isabel, sino que a través de los años ha incumplido su obligación de esclarecer los hechos, propiciando Ia repetición de hechos similares respecto de otras niñas.

2) Situación en el Perú

De acuerdo a la comisionada de la Adjuntía para los derechos de la mujer de la Defensoría del Pueblo Isabel Ortíz Urbizagástegui, durante el 2020 la situación de las mujeres desaparecidas ha sido más compleja que en años anteriores, ya que durante el año 2019, el 10\% de mujeres víctimas de feminicidio fueron reportadas como desaparecidas. Actualmente, hasta septiembre de 2020, de cada 100 víctimas de feminicidio, 25 habían sido denunciadas como desaparecidas. Es decir, un $25 \%$ de casos de feminicidio tiene como antesala una denuncia de desaparición. (OjoPúblico, 2020)

Así también, para esta institución, es preocupante el aumento de estas cifras, por lo que advirtió que, de las 127 víctimas de feminicidios registrados entre enero y noviembre, 33 habían sido reportadas previamente como desaparecidas. (Telesurtv.net, 2020) 


\section{DATOS ESTADÍSTICOS INTERNACIONALES Y NACIONALES}

Resulta imperativo en esta investigación la recopilación de datos estadísticos, que nos ayudarán a entender mejor el estado actual en torno a la desaparición de mujeres y niñas, no solo en el Perú, sino, además, en los países extranjeros. Asimismo, estos resultados pueden ser ocasionados por una diversidad de factores.

\subsection{INTERNACIONALES:}

Uno de los principales problemas por el cual estos temas no suelen ser abordados en las investigaciones viene a ser la falta de datos estadísticos en torno a este tema así lo afirma la OEA \& MESECVI (2018) "La desaparición de mujeres y niñas es una problemática que se ha identificado en diversos países del hemisferio.

A pesar de la falta de cifras estadísticas, algunas organizaciones de la sociedad civil e incluso agencias pertenecientes a los Estados Parte, han llevado a cabo registros al respecto." (p.5). Este problema también forma parte del Perú donde el INEI (Instituto Nacional de Estadística e Informática) la entidad encargada de brindar este tipo de datos en materia de desaparición solo llega a emitir datos en forma general sin realizar una diferenciación ya sea por sexo o edad. (Defensoría del pueblo, 2020)

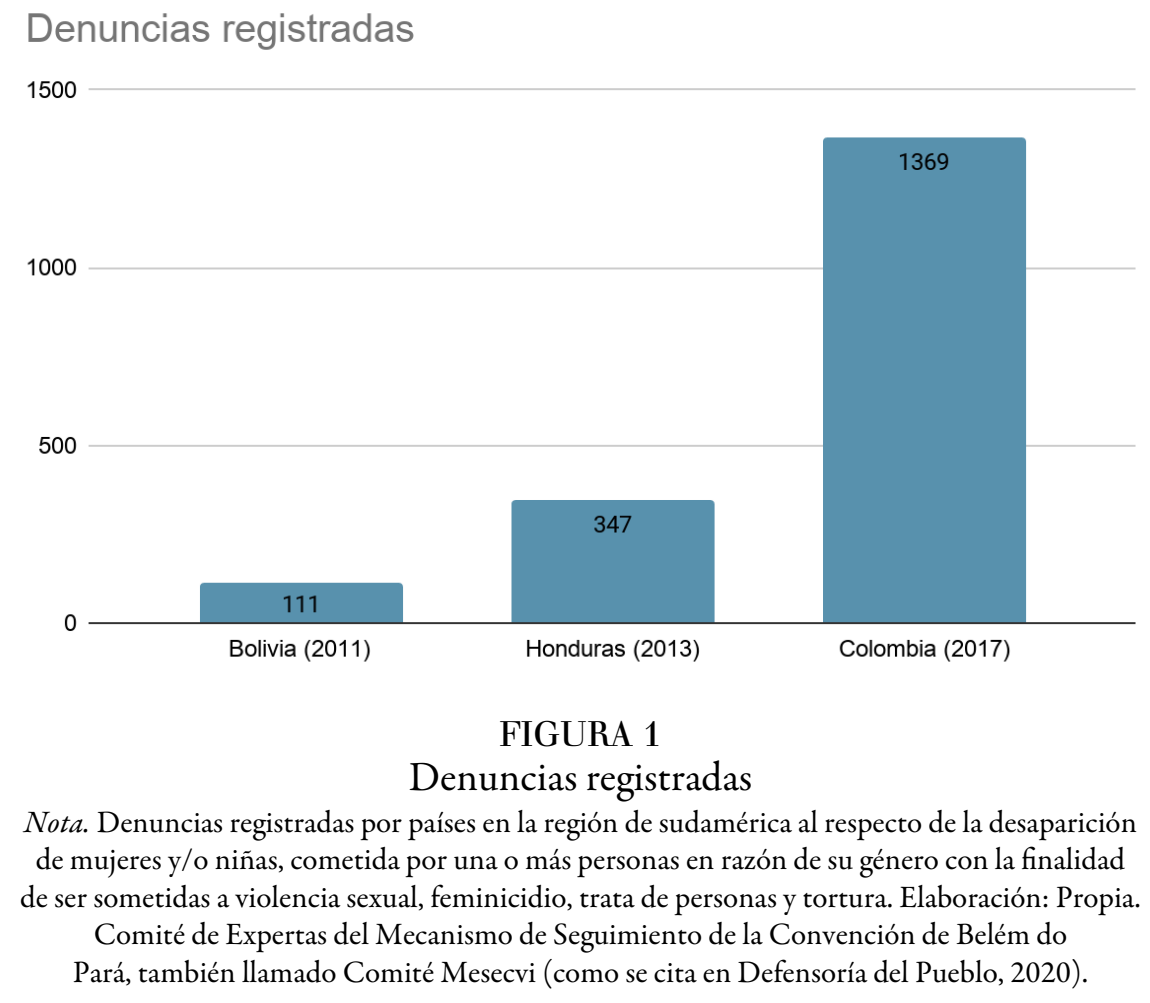

Si bien esta figura no muestra al Perú entre sus estadísticas resalta la finalidad con la cual se priva de la libertad a estas mujeres y/o niñas, que pasan a ser sometidas a distintos maltratos ya sean sexuales o físicos, los cuales pueden llevarlas a perecer. 


\section{PAÍSES CON MAS DESAPARICIONES FORZADAS EN EL MUNDO. Desapariciones entre los años 1980 y 2016}

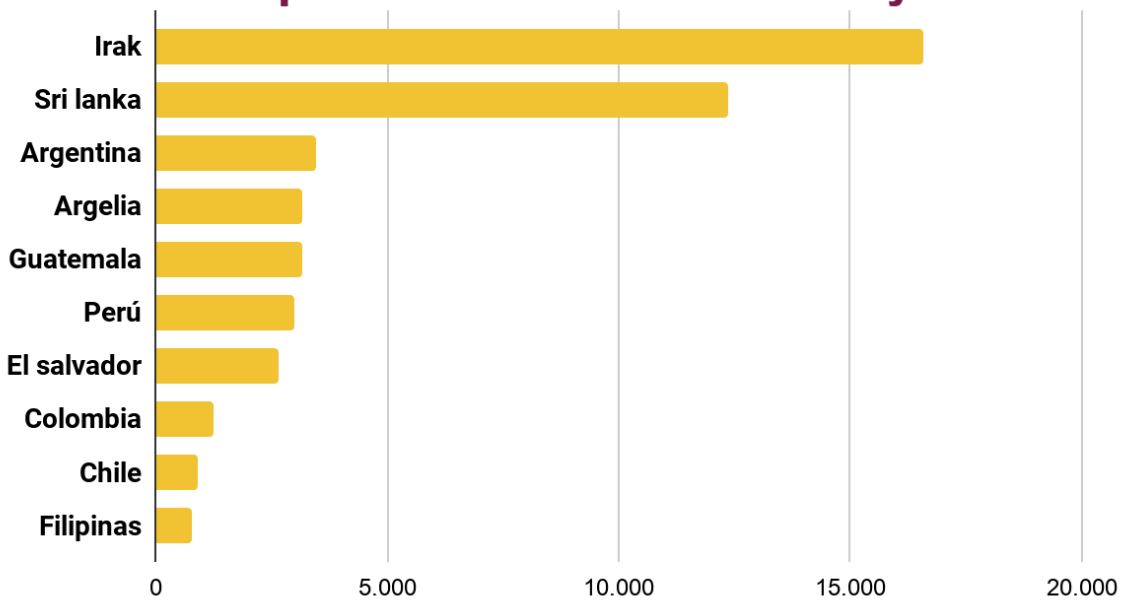

FIGURA 2

Nota: Total de casos en el mundo 55.273, resueltos 11.114 y 44.159 sin resolver. Elaboración: Propia. Alto comisionado de las Naciones Unidas para los Derechos Humanos.

\section{REGISTROS DE DESAPARICIONES EN AMERICA LATINA HASTA 2018.}

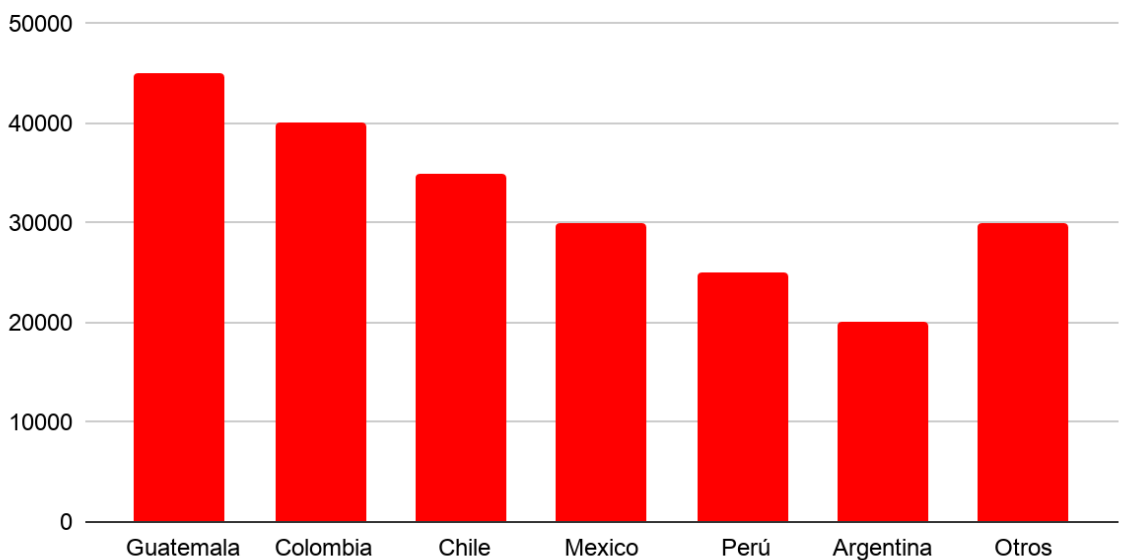

\section{FIGURA 3}

Nota. Elaboración: Propia.

Grupo apoyo mutuo (Guatemala), centro Nacional de memoria histórica (Colombia), comisión Nacional de la verdad y reconciliación (Chile), registro Nacional de personas extraviadas o desaparecidas (México), Ministerio

de justicia y Derechos Humanos (Perú), comisión Nacional sobre la desaparición de personas (Argentina).

Esta figura nos muestra a Perú bordeando las 25000 desapariciones registradas en América latina en el año 2018 ubicándolo en el quinto lugar superando a países como Brasil, quien posee una mayor población, lo cual llama la atención de manera alarmante ya que podemos apreciar un número exorbitante.

\subsection{NACIONALES.}

En nuestro ámbito nacional es por iniciativa de la defensoría del pueblo que ha inicios del año 2020 empezó a recopilar los datos estadísticos enfocados netamente al registro de denuncias de desaparición de mujeres y niñas en nuestro territorio. (Defensoría del Pueblo, 2020) 


\section{Cantidad de denuncias registradas en el SIDPOL por personas desaparecidas en el año 2020.}

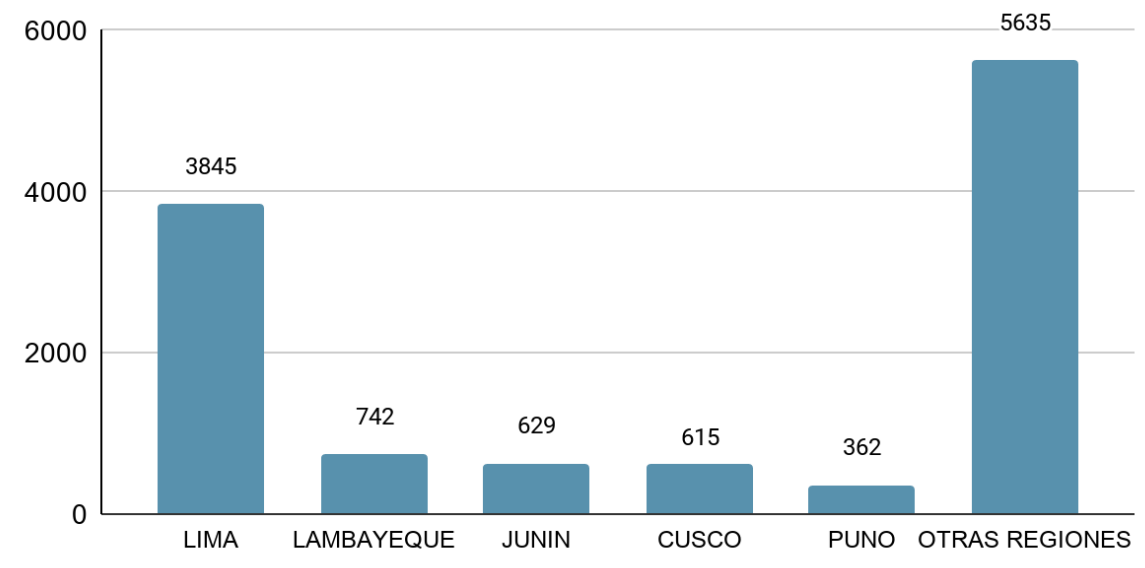

FIGURA 4

Nota: Datos de recopilados por el SIDPOL en todo el año 2020 este contaba con datos de personas masculinas y femeninas, sin embargo, por motivos de la investigación solo se estan tomando en cuenta los datos de las personas femeninas; no se tenía registro información por rango de edad. Elaboración: Propia. SIDPOL PNP.

Esta figura nos muestra una distribución total en el ámbito nacional de los reportes en materia de desaparición de mujeres donde se muestra un lógico número superior en la región de Lima, ya sea por su cantidad poblacional o por otras razones indeterminables por el momento que da como resultado un número abultado en esta región. Asimismo, da un pequeño atisbo de tranquilidad al ver que la región de Puno no forma parte de los territorios con mayor registro de denuncias de personas desaparecidas a comparación de: Lima, Lambayeque, Junín y Cusco. Sin embargo, esto también llama la atención debido a que el numero registrado en la región de Puno no es bajo en comparación con la cantidad poblacional que se tiene.

\section{Reporte de mujeres desaparecidas, niñas(os) adolescentes y varones desde el 16 de marzo y hasta el 30 de julio de 2020.}

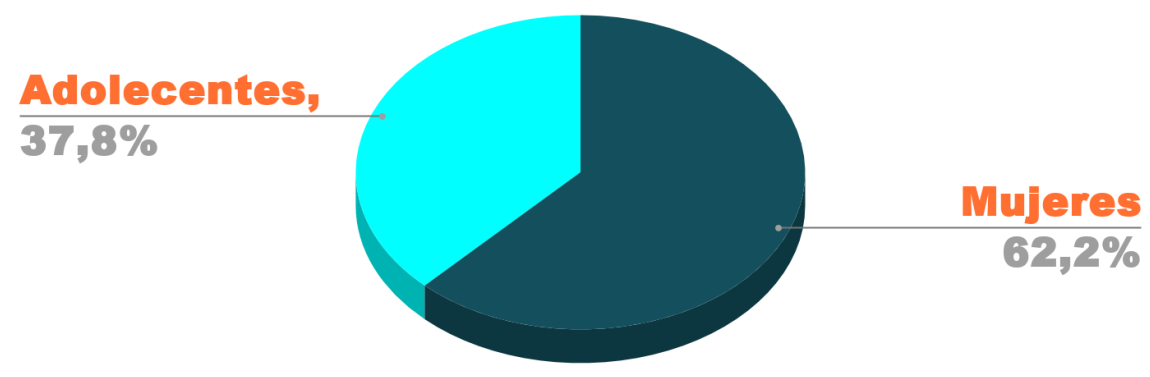

\section{FIGURA 5}

Nota: En el rango de meses del 6 de marzo y hasta el 30 de julio de 2020, la Policía Nacional del Perú (PNP) recibió 4448 denuncias por desaparición. Elaboración: Propia. Defensoría del Pueblo (Citado por Amnistía.org).

Los datos obtenidos nos indican que, en rango de edad de mujeres desaparecidas, predomina la desaparición de mujeres mayores de edad. 


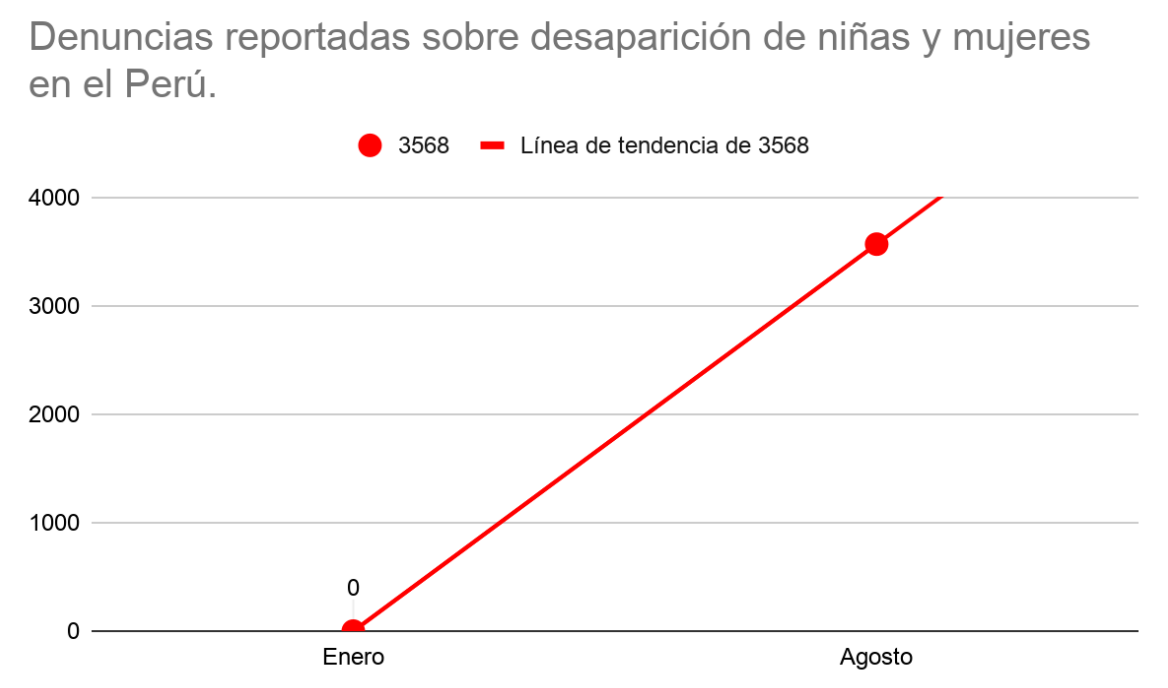

FIGURA 6

Nota: En el rango de meses de enero a agosto del año 2020 la Defensoría del Pueblo ha registrado el total de 3568 denuncias en materia de desaparición de niñas y mujeres en el Perú. Elaboración: Propia. Defensoría del Pueblo (Citado por Amnistía.org).

Las denuncias por desaparición en el territorio nacional han ido creciendo de manera llamativa sin parar en algún mes, el mismo accionar indica que aun con las medidas tomadas por el gobierno en la lucha contra la pandemia del Covid-19 no atenuaron este crecimiento.

\section{CASOS EMBLEMÁTICOS}

\subsection{Nacional}

Caso Camilita.

El 1 de marzo del 2020 Camila una niña de cuatro años, junto a su hermana de dos años, fueron dejadas bajo la custodia de una prima de nueve años, a las 05:30 a.m. fueron interceptadas por un adolescente que regresaba de una fiesta cercana, donde fue captado por las cámaras como tomó en brazos a Camila, mientras las pequeñas corrían tras de él en un intento por detenerlo. La menor fue violada y posteriormente asesinada. Su cuerpo fue abandonado en una bolsa y encontrado días después por la policía.

Este crimen ocurrió en Lima en el distrito de Independencia, donde los vecinos denunciaron los hechos antes los diversos gritos de las niñas, posteriormente al hecho la policía desplegó más de 250 efectivos quienes emprendieron la búsqueda que duró tres días, una de las dificultades fue que no se podía distribuir su foto por ser menor de edad.

Este caso causa estupor en el país debido a la poca responsabilidad de la madre, ya que, al momento en que se produjo el hecho ella se encontraba en una fiesta típica, esto llama a la reflexión no solo al tema legal en materia de pena de muerte solicitada por un sector poblacional o el cambio al ser el sujeto activo del delito menor de edad, además, de la falta de eficacia en materia de investigación de personas desaparecidas siendo demostrada en las pocas opciones de búsqueda que se incurrieron al tratarse de una menor de edad.

\subsection{INTERNACIONAL}

Caso de Cleveland. 
Este caso emblemático en materia de desaparición de mujeres que tuvo lugar en Estados Unidos, en Cleveland, Ohio en donde se suscitó el secuestro de Amanda Berry, Gina DeJesus y Michelle Knight. Este caso llamó la atención debido a que estas tres mujeres fueron privadas de su libertad entre nueve y once años, perpetrado por Ariel Castro, quien era natural de Puerto Rico que se mudó a Estados Unidos donde se instaló junto a su familia, quien terminó por divorciarse en 1996 de Crimilda Figueroa con quien tuvo tres hijos, la misma que interpuso diversas denuncias contra su exmarido por haber sido víctima de violencia física, llegando a sufrir lesiones en: costillas y dientes rotos e, incluso, un coágulo de sangre en el cerebro, con quien tuvo dos hijas Ariel y Arlene.

El primer secuestro fue a Michelle Knight el 23 de agosto de 2002 quien fue secuestrada al salir de la casa de su primo con dirección al tribunal, donde iba a comparecer en por la custodia de su hijo, al cual nunca llegó. El segundo secuestro lo realizó el 21 de abril de 2003, a la adolescente Amanda Berry un día antes de su cumpleaños número 17 cuando salía de su establecimiento de trabajo, una tienda de comida rápida Burger King, cuando Castro fingió ser el padre de un compañero incitando a que lo acompañara a su domicilio. Por último, raptó a Gina DeJesus de 14 años quien era amiga de una de sus hijas engañarla, haciéndole creer que visitan a Arlene lo cual nunca ocurrió.

Las mantuvo en condiciones infrahumanas, apenas recibiendo comida y bebida, además las sometió a toda clase de torturas físicas y sexuales, las mantuvo encadenadas y atadas con correas y bozales.

Encontraron el modo de salir el 6 de mayo de 2013, donde las jóvenes pudieron hallar la forma de pedir ayuda, logrando dar aviso a uno de los vecinos Charles Ramsey, quien llamó a la Policía y los que al estar llevando el caso de las tres desaparecidas presumían se trataba del mismo llegaron al lugar pusieron a salvo a las víctimas y esperaron a que Ariel Castro vuelva a su domicilio donde al recoger las pruebas incriminatorias que eran más de 200 procedieron a detenerlo, a sus 52 años Ariel Castro fue acusado de la cantidad de 977 cargos, por secuestro violaciones y torturas, además de provocar diversos abortos a las secuestradas, por lo cual, fue sentencia a cadena perpetua, sin posibilidad de fianza y a otros 1000 años de prisión.

Este caso resalta no solo por la cantidad de años que fueron secuestradas las tres mujeres sino además la falta de pistas y gran complicación al investigar los casos de personas desaparecidas, ya que, sin la lucha incesante de las tres mujeres por intentar escapar tal vez nunca hubieran logrado hallarlas.

Caso de Eva Blanco

Este caso ocurrió el 20 de abril de 1997 donde Ahmed Chelh asesinó a cuchilladas a Eva Blanco, quien tenía 16 años, dejándola en una zanja en la carretera que une Algete y Cobeña en Madrid, Eva salió el día anterior con sus amigas a divertirse a una discoteca de Algete, a las 23:30 horas Eva, salió con dirección a su casa acompañada de una de sus amigas, quien fue la última persona que la vio con vida, exceptuando a su asesino.

Al estar cerca de su casa, Eva se despide de su amiga y se encamina a su domicilio, donde fue interceptada por el Ahmed Chelh quien la agredió sexualmente y le asestó numerosas puñaladas. Dos de ellas le alcanzaron un órgano vital, para posteriormente ser abandonada en una zanja. Sus padres preocupados con el pasar de las horas y que su hija no llegara se apersonaron ante la Guardia Civil quienes encontraron su cuerpo sin vida, con diversas puñaladas, cabe resaltar que esa fue una noche donde estaba lloviendo y los muy pocos vestigios que pudieron ser recogidos fueron borrados por la lluvia, si se logró recoger una muestra de semen en los órganos genitales de la víctima.

Nada daba resultado en la exhaustiva investigación realizada, donde no se lograba dar con ninguna pista que llevará al asesino transcurrieron de esa forma 15 años donde la Guardia Civil tuvo que recurrir a la colaboración ciudadana, y es cuando una azafata al enterarse de este suceso, indico que la noche del crimen se había cruzado con una persona claramente sospechosa aportando un retrato-robot, reconstrucción plástica de una persona, el cual fue identificado como un hombre que había vivido años pasados en Algete. Y fue gracias a los estudios en materia forense que se logró dar con los resultados de la pequeña muestra de semen, los que habían sido obtenidos previamente, con una persona del norte de África, dando con Ahmed Chelh de 
52 años quien fue detenido el 1 de octubre de 2015, quien no reconoció ser autor del delito, finalmente el 9 de octubre una juez de Torrejón de Ardoz dictó su ingreso a la prisión, al no soportarlo terminó suicidándose en febrero de 2016.

Este caso es de suma importancia para el país de España, debido a, la gran cantidad de años que transcurrieron para poder resolverlo, asimismo, se hace imperativo el gran apoyo por parte de la ciudadanía al momento de resolverlo, debido a, que sin su apoyo no se habría logrado avanzar en las investigaciones porque se llegaron a investigar a mas de 2000 personas, asimismo, la declaración y descripción brindada por la azafata que ayudó en la ubicación del asesino.

Caso Etan Patz.

Este caso generó un gran impacto en la sociedad norteamericana, tanto que supuso la creación del Día Nacional de los Niños Desaparecidos (National Missing Children's Day) por parte del presidente Ronald Reagan en 1983. Etan fue uno de los primeros niños desaparecidos cuya foto apareció en los envases de leche.

Cuando despidió a su hijo de 6 años, esa mañana neblinosa (era el viernes 25 de mayo, de 1979) Julie Patz, mientras discutía con su hija mayor que no quería levantarse y se ocupaba del menor, Ari de solo dos años, que además había invitado a un amiguito a dormir, hablaba con Etan de los cuidados que debía tener en su primer día, largamente negociado, para ir caminando solo hasta el transporte escolar. Etan le había dicho un rato antes: "Está okey mamá, puedo hacerlo solo". Eran dos cuadras. Le dio el bolso decorado con elefantitos, lo besó, le palmeó la suave cabeza dorada, le estiró los pantalones azules y le acomodó la gorra de Eastern Airlines. Llevaba un dólar para comprarse una bebida en el camino. Así preparado, su madre lo acompañó hasta la puerta. Etan recorrería solo esos 200 metros, hasta la parada del bus escolar, pero los primeros pasos los hizo bajo la mirada atenta de su madre que, desde la puerta de entrada, estiraba el cuello para verlo a la distancia hasta que lo perdió de vista, hasta ese viernes 25 de mayo en el que Etan, no había subido al transporte escolar ni había llegado a su colegio. Poco después de hecha la denuncia, cien policías con perros salieron a las calles en su búsqueda. Helicópteros sobrevolaban la zona. Se buscaba a Etan puerta a puerta, mientras la sociedad en estado de shock quedaba presa de un miedo atávico: que un hijo se esfume sin rastro, Etan Kalil Patz nacido el 9 de octubre de 1972, fue declarado muerto el 2001 por un juzgado de Manhattan.

\section{CAMPAÑA BÚSCALAS IMPULSADA POR AMNISTÍA INTERNACIONAL - PERÚ}

El movimiento Amnistía Internacional fundado en 1961 por el abogado británico Peter Benenson, tiene como finalidad la de promover el reconocimiento y defensa de los derechos humanos a nivel global. Esta organización viene llevando a cabo junto a la Organización Mujeres Desaparecidas del Perú y al Centro de la mujer peruana Flora Tristán, la campaña Búscalas que tiene como objetivo visibilizar la problemática de las mujeres y niñas que desaparecen en la actualidad en el Perú para influir de esta manera en los planes y políticas públicas contra la violencia basada en género.

Ante la urgencia de implementar un sistema de búsqueda adecuado y oportuno de mujeres desaparecidas, se solicita lo siguiente:

1. Que el registro y portal de personas desaparecidas permita identificar el género y otros datos, como edad, nacionalidad, estado civil, orientación sexual, entre otros, y que proporcione información actualizada sobre la condición de las mujeres reportadas como desaparecidas, así como la posible relación de los hechos con otros delitos, como la violencia sexual, la trata de personas y el feminicidio.

2. Que se sistematicen las estadísticas de mujeres desaparecidas, se optimicen las notas de alerta y, en los casos necesarios, se emitan alertas de emergencia de manera efectiva a fin de agilizar el hallazgo de los casos reportados. 
3. Que se garanticen investigaciones pertinentes, rápidas y oportunas, considerando que las primeras 48 horas son cruciales y que las mujeres que desaparecen pueden ser víctimas de violencia sexual, trata y feminicidio.

4. Que se transversalice el enfoque de género y de derechos humanos en la búsqueda de mujeres desaparecidas para evitar actitudes y comportamientos discriminatorios, así como el uso de estereotipos de género que puedan afectar la valoración de las pruebas y la imparcialidad de la investigación.

5. Que se fortalezcan los servicios de atención integral, asistencia y apoyo a las víctimas y familiares de las mujeres desaparecidas.

6. Que se sensibilice a la población y se brinde información amigable sobre los procedimientos de denuncia y búsqueda ante este tipo de casos.

Hasta la fecha, ha sido capacitado un grupo de activistas que mediante diversas acciones orientadas a la población en general en todo el Perú (conversatorios, charlas virtuales, jornadas de difusión, presentaciones artísticas, difusiones por medios de comunicación y otros), vienen trabajando para alcanzar los objetivos planteados por la mencionada organización.

\section{CONCLUSIONES}

Concluimos que el entendimiento del delito de la desaparición aquella persona que se encuentra fuera de su domicilio a desaparecido involuntariamente, al cual no se le puede ubicar o no se tiene información de su paradero. Se entiende que el tipo de desaparición mas común es el realizado por particulares, siendo una de las modalidades más comunes por lo menos según lo denotado por las cifras internacionales, la desaparición de mujeres y niñas, a las cuales también se les suele someter a delitos aledaños como, feminicidio o torturas sexuales.

Si bien el accionar de las autoridades y las legislaciones emitidas, van en la misma dirección a lo establecido por las diversas entidades internacionales esto no resulta suficiente, muestra de ello es la falta de datos estadísticos en el Perú, al cual debemos hacer un llamado a las diversas entidades públicas para realizar una mejor recopilación de estos datos y darlos a conocer a la ciudadanía en general, ya que, esto podría contribuir a su prevención o a su resolución como el caso de Eva Blanco en España.

Las primeras 48 horas siguientes a la desaparición de una niña o mujer, son cruciales para llevar a cabo las diligencias de búsqueda e investigación a cargo de las autoridades correspondientes, ya que una demora en la misma, ocasionará mayor riesgo de peligro y muerte. Por este motivo, resulta de gran importancia la capacitación de funcionarios públicos en enfoque de género y respeto a los derechos de las mujeres.

Hasta la fecha, el Estado peruano no ha implementado una política pública especializada en la búsqueda de mujeres desaparecidas ni tampoco un registro de mujeres desaparecidas que adopte una perspectiva de género e igualdad de oportunidades para aquellos ciudadanos que decidan denunciar un hecho de desaparición de mujeres o niñas ante las autoridades correspondientes.

El más grande obstáculo para las diligencias de búsqueda por desaparición de mujeres es la deficiente actuación por parte de las autoridades estatales (Policía, Ministerio Público y Poder Judicial), las justifican este accionar en estereotipos de género prevalecientes en diversos países de América Latina. Por este motivo, resulta de gran importancia la capacitación de funcionarios públicos con enfoque de género y respeto hacia los derechos de las mujeres. 


\section{REFERENCIAS}

Árez, L. Buitrago, L. \& Fajardo, G. (2019). Mendicidad ajena como modalidad del delito de trata de personas. Caso embera-chamí. https://dialnet.unirioja.es/descarga/articulo/6860274.pdf

Anaya de Pauta, B. S. (2012). El feminicidio: un atentado contra la dignidad de la mujer. Revista de Investigación Jurídica. IUS. 02(3), 2012. https://bv.unir.net:3555/es/ereader/unir/28017?page=1.

Arese, M. C. (2019). Convenio sobre la abolición del trabajo forzoso, 1957 (núm. 105). Relaciones Laborales y Derecho del Empleo. Recuperado el 8 de enero del 2021 de https://ejcls.adapt.it/index.php/rl de_adapt/article/viewFile/726/940

Bernstein, E. (2014) ¿Las políticas carcelarias representan la justicia de género? La trata de mujeres y los circuitos neoliberales del crimen, el sexo y los derechos. Debate Feminista. (50) pp. 280-320. https://www. sciencedirect.com/science/article/pii/S0188947816301396

Cendejas Jáuregui, M., Pérez Morales, V., Rivas Rodríguez, F. \& Fernández Hernández J. A. (2014). Un ejercicio de acceso a la información sobre la eficiencia en el combate contra la trata de personas en México. Revista Mexicana de Opinión Pública, (16), pp. 112-135. https://www.sciencedirect.com/science/article/ pii/S1870730014723300

Cervantes, M. (2015). La participación social en familias víctimas de desaparición involuntaria. RICSH Revista Iberoamericana de las Ciencias Sociales y Humanísticas. https://www.redalyc.org/pdf/5039/5039 50656004.pdf

CHS Alternativo (2010) La Trata de Personas en el Perú manual para conocer el problema. Autoedición. Recuperado el 26 de diciembre de 2020 de https://www.trabajo.gob.pe/migrante/pdf/trata_personas_per u_manual.pdf

CHS Alternativo (2018) Personas Desaparecidas. Recuperado el 6 de enero del 2021 de https://chsalte rnativo.org/personas-desaparecidas/

Coca, S. (2020) Desaparición, ausencia y muerte presunta en el Código Civil peruano. Bien explicado. Legis.pe. Recuperado el 8 de enero del 2021 de https://pderecho.pe/desaparicion-ausencia-muerte-presun ta-codigo-civil-peruano/

Congreso de la República del Perú. (15 de septiembre del 2018). Decreto Legislativo que desarrolla medidas para la atención de casos de desaparición de personas en situación de vulnerabilidad. (Decreto Legislativo No 1428). Recuperado el 26 de diciembre de 2020 de: https://busquedas.elperuano.pe/normasl egales/decreto-legislativo-que-desarrolla-medidas-para-la-atencion-decreto-legislativo-n-1428-1692078-3/

Convención Internacional para la Protección de Todas las Personas contra las Desapariciones Forzadas (2006). Naciones Unidas. https://www.ohchr.org/SP/ProfessionalInterest/Pages/ConventionCED.aspx

Convención Interamericana para prevenir, sancionar y erradicar la violencia contra la mujer. (1994). Organización de los Estados Americanos. https://www.oas.org/es/mesecvi/docs/BelemDoPara-ESPANO L.pdf

Defensoría del Pueblo (2017). Trata de personas con fines de explotación sexual en agravio de mujeres adultas. Estudio de casos en las regiones de Lima, Madre de Dios, Piura, Pasco, Lambayeque, Huánuco y Cusco. Recuperado el 26 de diciembre de 2020 de: https://www.defensoria.gob.pe/wp-content/uploads/2 018/05/I.A--041-2017-ADM--trata-de-mujeres.pdf

Defensoría del Pueblo (2020). La desaparición de mujeres cometida por particulares: Marco regulatorio, legislación comparada y situación de la problemática en el Perú. Serie Igualdad y No Violencia 2020 N$^{\circ} 003$ Autonomía física. Autoedición Recuperado el 26 de diciembre de 2020 de: https://www.defensoria.gob.pe /wp-content/uploads/2020/06/Informe-desaparecidas.pdf

Defensoría del Pueblo (2020) ¿QUÉ PASÓ CON ELLAS? Reporte Igualdad y No Violencia.N 1. Autoedición. Recuperado el 26 de diciembre de 2020 de https://www.defensoria.gob.pe/wp-content/uplo ads/2020/03/Reporte-de-Igualdad-y-No-Violencia-N\%C2\%B0-1.pdf 
Giménez-Salinas Framis, A. (2011). La explotación y trata de mujeres con fines sexuales: el papel del sector salud. Gac Sanit. 25(5), pp. 351-352. http://scielo.isciii.es/scielo.php?script=sci_arttext\&pid=S0213-9111 2011000500001

Guajardo, G. \& Cenitagoya, V. (2017). Feminicidio y suicidio de mujeres por razones de género. Desafíos y aprendizajes en la cooperación Sur-Sur en América Latina y el Caribe. https://www.corteidh.or.cr/tabla s/r37317.pdf

Hernández, R. (2005). Explotación sexual comercial. Recuperado el 8 de enero del 2021 de https://ww w.corteidh.or.cr/tablas/24866.pdf

INTERPOL. (2020, 12 18). Trata de personas. Interpol. https://www.interpol.int/es/Delitos/Trata-de -personas

INTERPOL. (2021). Tipos de trata de personas. Recuperado el 8 de enero del 2021 de https://www.int erpol.int/es/Delitos/Trata-de-personas/Tipos-de-trata-de-personas

Ministerio de Justicia y Derechos Humanos. (2017). TRATA DE PERSONAS EN EL PERÚ. Criminología de actores y perfiles penitenciarios. https://indagaweb.minjus.gob.pe/wp-content/uploads/2 019/08/Trata-de-personas-en-el-Peru.pdf

Ministerio del Interior. (2020). Registro Nacional de Información de Personas Desaparecidas (RENIPED). Recuperado el 26 de diciembre del 2020 de, https://desaparecidosenperu.policia.gob.pe/Des aparecidos/reniped

Naciones Unidas Oficina contra la droga y el delito. (2000). Convención de las Naciones contra la Delincuencia Organizada Transnacional.

https://www.unodc.org/documents/treaties/UNTOC/Publications/TOC\%20Convention/TOCebo ok-s.pdf

Organización Internacional del Trabajo. (1930). Convenio sobre el trabajo forzoso, 1930 (núm. 29)

Organización Internacional del Trabajo. (2002). Informe Global "Un futuro sin trabajo infantil". Informe del Director General de la OIT. Conferencia Internacional del Trabajo 90a. Reunión. http://www.cnasti. $\mathrm{pt} / \mathrm{cnasti} /$ documentos/1403450585.pdf

Organización Internacional del Trabajo (2021). Qué es el trabajo forzoso, las formas modernas de esclavitud y la trata de seres humanos. Recuperado el 15 de enero de 2021 de, https://www.ilo.org/global/ topics/forced-labour/definition/lang--es/index.htm

Pacecca, M. (2011). Trabajo, explotación laboral, trata de personas. Categorías en cuestión en las trayectorias migratorias. REMHU-Revista Interdisciplinar da Mobilidade Humana. Recuperado el 8 de enero del 2021 de https://www.redalyc.org/pdf/4070/407042014009.pdf

Pomares, E. (2011). El delito de trata de seres humanos con finalidad de explotación laboral. Revista electrónica deficiencia penal y criminología, 13 (15). Recuperado el 8 de enero del $2021 \mathrm{de} \mathrm{http://crimine}$ t.ugr.es/recpc/13/recpc13-15.pdf

Red Para La Infancia y la Adolescencia. (2009). Informe de sociedad civil sobre aspectos claves en el cumplimiento del protocolo facultativo relativo a la venta de niños, la prostitución infantil y la utilización de niños en la pornografía. Recuperado el 8 de enero del 2021 de https://resourcecentre.savethechildren.n et/sites/default/files/documents/4442.pdf

Salamanca, E. (2003). El Protocolo facultativo relativo a la venta de niños, la prostitución infantil y la utilización de los niños en la pornografía. Recuperado el 8 de enero del 2021 de https://abacus.universidad europea.es/bitstream/handle/11268/4922/Salamanca_Aguado2003.pdf?sequence $=1$

Tejada, M. (2016). La trata de personas en el Perú, análisis y perspectiva. Revista Oficial del Poder Judicial. Recuperado el 8 de enero del 2021 de https://revistas.pj.gob.pe/revista/index.php/ropj/article/view/246

Uribe Olvera, M. (2013) Facultad legislativa del congreso de la unión respecto de la trata de personas. Cuestiones Constitucionales. (28), pp. 353-361. https://www.sciencedirect.com/science/article/pii/S1405 919313712848 

INTERN...

Velarde Vargas, O. I., \& Yabarrena Tamayo, J. S. (2018). Sistema de reconocimiento facial para el control de la trata de personas en Perú. Revista de la Facultad de Ingeniería y Arquitectura. Recuperado el 8 de enero del 2021 de https://revistas.uandina.edu.pe/index.php/mastariy/article/view/171

Varillas, W. (2003). La red sobre trabajo infantil peligroso (Red Tip). Ciência \& Saúde Coletiva. Recuperado el 8 de enero del 2021 de, https://resourcecentre.savethechildren.net/sites/default/files/docu ments/4442.pdf 